УдК 331.101.5:331.52-053.81

\title{
ВЛИЯНИЕ ЦИФРОВОЙ ЭКОНОМИКИ НА ТРУДОВЫЕ ЦЕННОСТИ ПОКОЛЕНИЯ, ВХОДЯЩЕГО НА РЫНОК ТРУДА
}

\author{
Аранжин Вячеслав Викторович, \\ slava.mr.slava@mail.ru \\ Национальный исследовательский Томский государственный университет, \\ Россия, 634050, Томск, пр. Ленина, 36.
}

\begin{abstract}
Аранжин Вячеслав Викторович, аспирант кафедры стратегического менеджмента и маркетинга Института экономики и менеджмента Национального исследовательского Томского государственного университета.
\end{abstract}

\begin{abstract}
Актуальность исследования заключается в том, что цифровая экономика оказывает значительное влияние на все без исключения сферы общественной жизни: совершаемые трансакции, ведение бизнеса и бизнес-модели организаций, способы коммуникаций между субъектами, на образ жизни людей, труд, досуг. Молодое поколение, которому только предстоит войти на рынок труда, родилось в эпоху цифровых технологий, что, безусловно, повлияло на их ценности и модели поведения, 8 связи с чем возникает необходимость оценки влияния цифровой экономики на трудовые ценности поколения, входящего на рынок труда. Исследование трудовых ценностей поколения $Z$ поможет организациям (работодателям) разрабатывать эффективные стратегии мотивации, удержания, создания условий работы, соответствующих ценностям данного поколения. Цель: определение механизмов влияния цифровой экономики на трудовые ценности поколения, входящего на рынок труда. Методы: исторический метод, методы логического, сравнительного, системного анализа. Результаты. Рассмотрены основные особенности цифровой экономики, проведен анализ основных характеристик поколения $Z$ на основании обзора зарубежной и отечественной литературы, определены трудовые ценности поколения $Z$ и дана оценка влияния цифровой экономики на трудовые ценности рассматриваемого поколения. Выдвинуто предположение о том, что цифровая экономика не является единственным фактором, оказывающим влияние на трудовые ценности современного поколения.
\end{abstract}

Ключевые слова: Цифровая экономика, четвертая промышленная революция, цифровые технологии, поколение Z, трудовые ценности, рынок труда, трудовые отношения, мотивация.

\section{Введение. Постановка вопроса}

Цифровые технологии кардинальным образом меняют все сферы общественной жизни. Экономика не является исключением. В конце XX в. произошли кардинальные изменения, которые стали началом нового скачка в рамках четвертой промышленной революции и тесно связанной с ней цифровизации экономики [1]. Цифровая революция порождает взаимодействие между виртуальным и физическим производством. Сегодня информация является основным источником богатства. Весь мир оказывается погруженным в экономику нового типа [2]. Сегодня развиваются электронная коммерция и электронный рынок, которые влияют на перестройку компаниями собственных бизнеспроцессов. Электронная торговля оказывает воздействие не только на экономические, но и на социальные структуры и процессы. 
Цифровая экономика, помимо прочего, приводит к изменению моделей принятия решений, бизнес-моделей и моделей поведения потребителей. Благодаря цифровизации происходит появление целого ряда явлений: всеобщее доступное подключение к сети Интернет, внедрение цифровых платформ, развитие инфраструктуры для хранения и обработки информации, технологии обработки больших данных, доверенное цифровое пространство (подобное пространство приводит к вовлечению бизнеса и населения в цифровую экономику) [3]. Также происходит появление таких технологий, как искусственный интеллект, туманные вычисления, квантовые технологии, суперкомпьютерные технологии, технологии идентификации, математическое моделирование, сквозные технологии, технологии блокчейна, нейронные сети, киберфизические системы, технологии в области аддитивного производства, роботизация, технологии открытого производства, беспилотные технологии, безбумажные технологии, мобильные технологии, биометрические технологии, технологии «Мозг-компьютер» и т. д. На фоне этого происходит формирование новых рынков и новых потребностей, основанных на применении цифровых технологий.

В результате цифровизации экономики в обществе наблюдается целый ряд тенденций: повышение мобильности и значимости информации, использование обработанных данных для принятия управленческих решений, распространение сетевых эффектов, повышение важности системы управления знаниями; государства и компании создают экономические объединения в целях объединения ресурсов. Это приведет и уже приводит к тому, что традиционные предприятия начнут испытывать трудности. В связи с этим постоянные преобразования бизнес-моделей, ориентация на цифровые стратегии и использование информации в принятии управленческих решений должны стать нормой.

Безусловно, цифровая экономика, помимо всего вышеперечисленного, оказывает влияние и на рынок труда. В настоящем исследовании рассматривается влияние цифровой экономики на трудовые ценности поколения, входящего на рынок труда, а также перечень трудовых ценностей, сформированных под влиянием цифровой экономики. Для того чтобы понять влияние цифровой экономики на поколение, входящее на рынок труда, проанализируем основные признаки поколения Z. По различным зарубежным и отечественным источникам (мнения расходятся) поколение $\mathrm{Z}$ - люди, дата рождения которых начинается в период с 1995 по 2010 г. Данное поколение в ближайшие 3-5 лет станет активным субъектом рынка труда и активно начнет вступать в трудовые отношения [4]. Исследование трудовых ценностей поколения $\mathrm{Z}$ поможет организациям (работодателям) разрабатывать эффективные стратегии мотивации, удержания, создания условий работы, соответствующих ценностям данного поколения.

\section{Обзор литературы}

Теория поколений была сформирована в результате исследований Уильяма Штрауса и Нила Хоу [5]. В основе данной теории заложено понимание поколения как группы людей, родившихся в определенный временной промежуток, попавших под влияние одних и тех же событий и особенностей воспитания, а также имеющих аналогичные ценности. Именно ценности и определяют поведение представителей того или иного поколения. По мнению авторов теории поколений [6], история циклична. Длительность каждого цикла составляет периоду примерно в 80-90 лет. И каждый цикл состоит из четырех периодов, в каждом из которых преобладают какие-либо определенные ценности и установки. Помимо прочего, авторы также выделяют два противоположных периода: период подъема и период кризиса. В периоды кризиса общество на- 
чиняет объединяться, готово к самопожертвованию и стремится к порядку, а в периоды подъемов преобладает индивидуализм, а государственные институты подвергаются критике.

Согласно данной теории, на текущий момент представлены следующие поколения: поколение Победителей, Молчаливое поколение, поколение Беби-Бумеров, поколение X, поколение Миллениум, или Y, и поколение Z.

Существует большое количество отечественных и зарубежных исследований ценностей, ценностных ориентаций. В зарубежной литературе исследования отражены в работах М. Вебера, Э. Дюркгейма, Ф. Знанецкого, Т. Парсонса, М. Рокича, У. Томаса и т. д. В отечественной литературе это работы Н.А. Журавлевой, А.Г. Здравомыслова, Н.И. Лапина, Г.В. Осипова, И.М. Поповой, В.П. Тугаринова, В.А. Ядова и др. Изучением трудовых ценностей занимались В. Франкл, Д. Майнер, Д. Коллинз, Д. Доуз, С. Шварц, С. Роббинс, Е. Шейн, Х. Варнеке, Д. Чатмен, М. Рокич, А. Сакс, В. Радаев, Н. Шаталова, К. Харский, Е.Г. Антосенков, Б.Г. Бессонов, Н.Г. Валентинова, Т.И. Заславская, О.Л. Краевая и др.

Однако несмотря на столь глубокую изученность трудовых ценностей в самых различных аспектах, существует очень мало исследований трудовых ценностей поколения, которому в ближайшем будущем только предстоит выйти на рынок труда. Актуальность исследований заключается в том, что в ближайшем будущем поколение Z начнет активно входить в рынок труда, в связи с чем работодателям при выстраивании взаимоотношений с ними крайне важно понимать их ценности и установки, в частности трудовые.

\section{Основные результаты исследования}

На сегодняшний день наиболее активным на рынке труда является поколение Y, родившееся в период с 1977 по 1994 г., на формирование которого значительно повлияли развитие цифровых технологий, замена живого общения виртуальным. Данное поколение является амбициозным, общительным, либеральным, склонным к изменениям, трудоспособным, увлеченным рабочим процессом. Однако им тяжело находиться в длительных проектах, для них важен интерес и разнообразие в трудовой деятельности. Они фактически всегда находятся в зоне доступа, на связи, но считают, что технологии размывают границы между работой и личной жизнью [4].

Поколение $\mathrm{Z}$ пока не проявляет себя ввиду возраста и по причине, что данное поколение прозвано «молчаливым» [5]. Считается, что они не планируют на длительный промежуток времени, поскольку для них уже привычна быстроменяющаяся реальность, и долго находиться в одном состоянии, учитывая ускорение процесса изменений, не стоит [7].

Поколение $\mathrm{Z}$ возникло под воздействием всеобъемлющих виртуальных социальных сетей, повсеместного Интернета, террористических действий и экономических кризисов. Данное поколение еще называют «цифровыми аборигенами». Помимо всего прочего, данное поколение является гибким, чувствительным, неагрессивным, бесконфликтным, сосредоточенным внутри себя, стремящимся формировать новые каноны этики и эстетики. Они находятся в Интернете 24 часа в сутки, 7 дней в неделю. Технологии являются частью их обычной жизни $[7,8]$.

Часть исследователей выделяет около тридцати характеристик нового поколения. В результате социологических исследований были выделены такие основные, как индивидуальность и уникальность, поиск смыслов, гибкость и компромиссность, ценность личных опыта и чувств [7]. В 2008 г. социологами было зафиксировано, что мир 
перестал жить в рамках одной мелодии. Усложнение социальной реальности создает необходимость реализации человеком своего индивидуального потенциала, в связи с чем возрастает спрос на уникальность. Представители нового поколения не любят, когда их сравнивают с другими. Индивидуальность - это образ их быта. Представитель нового поколения свободно может жить без политики, нотаций и т. д. Виртуальность и реальность для поколения Z, в отличие от их родителей, - одно и то же [7].

Весь мир сегодня в буквальном смысле тонет в информационном потоке, который меньше не становится. Новое поколение существенно дозирует потребление информации сознательно, стараясь осмыслить то, что допускает. Смыслы и предназначения вот что имеет для поколения $\mathrm{Z}$ особое значение. В связи с этим внешняя мотивация для этого поколения будет иметь меньшее значение, чем для предыдущих поколений. У них также уменьшится количество авторитетов. Это поколение призвано обновлять жизнь, исправлять ошибки других поколений и наполнять социальное пространство новыми смыслами. Они также атипичны, поэтому тяжело будет дать их общий портрет [7].

Поколение Z, рожденное в эпоху стремительной цифровизации экономики, свободно владеет цифровыми технологиями, что потенциально дает для них возможность, при взаимодействии с машинами, освободить время для творчества.

Также можно выделить признаки в поведении поколения Z на рынке труда: инфантилизм и самодостаточность, смыслы и нематериальная мотивация труда, индивидуальность и уникальность, экономия сил и сужение сферы профессиональных интересов, гибкость и мобильность, личностный потенциал и профессиональная самореализация, опыт и инновации. Материальное стимулирование по-прежнему работает, но оно не является доминирующим по отношению к поколению Z. Работодателям придется создавать для поколения $\mathrm{Z}$ мир с миссией и ценностями, демократической культурой, a работников рассматривать как инвесторов с потенциалом. Данное поколение также будет плохо относиться к бюрократии, может быть неготовым к трудностям и нестандартным ситуациям. Сама профессиональная деятельность потеряет главную роль в жизни молодого поколения [7].

Из анализа особенностей цифровой экономики и поколения $\mathrm{Z}$ можно сделать вывод о том, что цифровая экономика оказала непосредственное влияние на формирование особенностей рассматриваемого поколения. Выделим основные:

1. Виртуальный мир и реальность для данного поколения не имеет разницы, для них это одно и то же. Все, что связано с виртуальными технологиями, повсеместным Интернетом и т. д., является результатом внедрения цифровых технологий в повседневную деятельность. Как уже говорилось выше, поколение $\mathrm{Z}$ уже родилось в эпоху цифровизации.

2. Поколение $\mathrm{Z}$ является, по отношению к другим поколениям, более мобильным. Это вытекает из того, что данное поколение, родившись в эпоху цифровизации, общается с продуктами данного процесса на «ты», за счет чего и достигается повышенная мобильность.

3. Готовность к инновациям связана с тем, что поколение $\mathrm{Z}$ живет в цифровой среде изначально, и ускоряющиеся темпы технологического развития не вызывают у них серьезного сопротивления. Они активно готовы потреблять новые технологии, в связи с чем инновации и инновационная деятельность являются для них более привычными.

4. В то время как мир тонет в информационном потоке, поколение Z умеет ориентироваться в этом объеме информации, отсеивая то, что им не нужно, и усваивая то, что соответствует их смыслам и ценностям. 
Очевидно, что цифровизация оказала сильное влияние на формирование особенностей поколения Z. Возникает закономерный вопрос: как под воздействием цифровой экономики изменились трудовые ценности данного поколения и какие стратегии (найма, мотивации, удержания, обучения и развития) должны применять работодатели к поколению $\mathrm{Z}$ с учетом их трудовых ценностей?

Можно предположить, что с учетом обозначенных выше особенностей поколения $\mathrm{Z}$, сформированных под воздействием цифровизации экономики, трудовые ценности данного поколения также претерпели существенные изменения и они существенно отличаются от трудовых ценностей предшествующих поколений.

В целях подтверждения данной гипотезы проведем анализ трудовых ценностей поколения Z.

Согласно данным российского журнала «Эксперт online» [9], для поколения Z для ощущения благополучия наибольшую ценность имеют: здоровье, семья, друзья, удовлетворенность учебой или работой, качественная социальная жизнь и время отдыха, но и достойный уровень дохода для комфортной жизни. С позиции идеальной работы рассматриваемое поколение имеет следующие приоритетные трудовые ценности: возможность для саморазвития, уровень заработной платы, возможность для продвижения, возможность путешествовать, встречаться с новыми людьми и возможность улучшить мир. Меньше всего для них важен статус, знаменитость и известность. Также отметим, что в большей степени поколение $\mathrm{Z}$ беспокоят деньги, давление в школе, здоровье, семья и друзья. В свою очередь, в большей степени они надеются на технологические достижения, доступное хорошее образование, глобальное распространение демократии и прав человека, Интернет как способ достижения эффективной коммуникации. Меньше всего они надеются на религию и веру.

Несмотря на то, что заинтересованность в доходе у поколения $\mathrm{Z}$ есть, она имеет не определяющее значение. Поскольку это поколение, родившееся в эпоху цифровизации и технологического развития, они в большей степени надеются на технологии и Интернет, доступный в любой точке мира. Низкая ценность статуса и известности еще раз подтверждает то, что для поколения $\mathrm{Z}$ не существует авторитетов, а наиболее важным является возможность саморазвития.

По мнению О.В. Решетникова [7], для поколения $\mathrm{Z}$ важна личная автономия. Это значит, что на рабочем месте они будут готовы в одиночку справляться с большинством задач и проблем. Также они будут находиться, в т. ч. и на рабочем месте, в поисках смыслов, предназначений, т. е. если работа не имеет для них смысла, вряд ли они долго там задержатся. Более того, на работе они будут искать различные формы самовыражения. Также в связи с цифровизацией, данное поколение, родившееся в период постоянных перемен, является мобильным и готово к постоянным изменениям. Именно по этой причине они не заглядывают слишком далеко в будущее. Материальное стимулирование перестает быть для них важнейшим фактором при выполнении каких-либо задач. Они, к тому же, стремятся к реализации своего потенциала, в связи с чем будут приветствовать различные формы гибкой организации труда.

Помимо прочего, О.В. Решетников также отмечает, что поколение $\mathrm{Z}$ крайне восприимчиво к технологиям и инновациям. Технологии для них - это само собой разумеющееся, что-то обыденное. Данному поколению требуются задачи «на вырост», которые превосходят их возможности, но позволяют реализовать потенциал, осуществить собственный вклад в реализацию какой-либо задачи.

В исследовании «Трудовые ценности и установки студенческой молодежи» [10] отмечается, что несмотря на важность труда для молодого поколения, он не является 
центральным явлением в их жизни, в то время как самореализация становится одним из центральных понятий. В.П. Кошарный отмечает, что ценность работы для них располагается только на четвертом месте [10]. Работа, в свою очередь, должна быть интересной; также автор отмечает важность карьерного роста для молодого поколения. Однако, заметим, что несмотря на то, что материальная составляющая также выделяется как одна из важнейших ценностей, в первую очередь достижение материального благополучия важно лишь для приобретения необходимых вещей.

В исследовании НИУ Высшая школа экономики [11] отмечаются следующие основные характеристики поколения Z: высокая вовлеченность в мультимедийные технологии, нетерпеливость по отношению к технологиям, ориентация на потребление и индивидуализм, высокая ценность честности и откровенности, самообразование посредством интернет-технологий, многозадачность, низкая концентрация внимания и отличное от других поколений функционирование памяти (запоминается путь поиска информации), восприятие информации меньших объемов, гиперактивность и погружение в себя. С точки зрения трудовых ценностей, согласно исследованию, для данного поколения наиболее важны:

- нацеленность на получение прибыли;

- заинтересованность в трудных заданиях как в возможности самовыражения;

- предпочтение остаться частью коллектива без стремления к самостоятельности;

- ценность результативности общего дела, к которому имеет причастность.

Исследование, проведенное НИУ ВШЭ, также подтверждает вывод, что среди трудовых ценностей материальная составляющая имеет большое значение. Однако, помимо этого, прослеживается явная ориентация на результат, стремление выполнять задания «на вырост» и стремление к самореализации.

Согласно данным Forbes [12], поколение Z готово начать работать значительно раньше, чем на это рассчитывают работодатели. При том ради работы это поколение может отказаться от традиционного обучения в университете, компенсируя это другими способами получить хорошее образование. Также для поколения $\mathrm{Z}$ важно, чтобы работодатель активно управлял собственным брендом, к примеру, отвечал на отзывы, обновлял свой профиль и т. д. Около 77 \% представителей поколения $\mathrm{Z}$ говорят, что уровень разнообразия в компании влияет на их решение работать там. Поэтому работодателю необходимо формировать атмосферу разнообразия на рабочем месте. Также данное поколение заинтересовано в наличии нескольких ролей на одной работе. В связи с этим организационная структура компании должна быть гибкой и подвижной. Также работодателям следует предлагать поколению $\mathrm{Z}$ больше возможностей для обучения и развития в самых разнообразных формах, в том числе и с использованием цифровых технологий. Объем материала для обучения не должен превышать 15 минут, если он представлен в видеороликах.

На основании анализа отечественной и зарубежной литературы в области исследования трудовых ценностей поколения $\mathrm{Z}$ мы пришли к ряду заключений.

В первую очередь обратим внимание на ряд различий, имеющийся у исследователей, при анализе трудовых ценностей. Одни исследователи утверждают, что для поколения Z важна коллективная работа и командный дух, достижение общего результата, в то время как другие утверждают, что данное поколение нацелено на самостоятельную, индивидуальную работу. Также неоднозначным является утверждение, что для поколения $\mathrm{Z}$ важен карьерный рост. Однако данный вывод был сделан только в одном из рассмотренных нами исследований.

Но все же, несмотря на некоторые отличия, сходств больше. 
Во-первых, все авторы сходятся в том, что важна оснащенность рабочего пространства цифровыми технологиями, и это является одной из ключевых ценностей, т. к. они позволяют реализовать потенциал рассматриваемого нами поколения.

Во-вторых, для поколения $\mathrm{Z}$ важна организационная гибкость: гибкость структуры, гибкость в задачах, возможность попробовать себя в разных ролях, гибкость форм занятости.

В-третьих, для рассматриваемого поколения важна самореализация и самовыражение. Ради этого они готовы брать задачи «на вырост», чтобы развивать себя. Однако стоит отметить, сама работа для них не является первостепенной: если задачи, которые перед ними поставлены, им интересны, то тогда они готовы выкладываться.

В-четвертых, данное поколение заинтересовано в наращивании объема знаний и навыков, готово учиться. Однако обучение в традиционном смысле для них становится менее актуальным, поэтому работодателям стоит позаботиться о разнообразных, в том числе и цифровых, формах обучения.

B-пятых, материальная составляющая для поколения Z также важна, однако она не имеет первостепенного значения и необходима лишь для удовлетворения актуальных потребностей.

На основании проведенного анализа можно утверждать, что такие ценности, как доступ к цифровым технологиям и поддержка инноваций в решении задач, гибкость, потребность в постоянном обучении, сформированы именно цифровой революцией. Поскольку гибкость, доступное и вариативное образование, цифровые технологии - это те возможности, которые сформированы именно цифровыми технологиями. Также отметим, что цифровая экономика сделала доступными большой объем данных, в связи с чем поколение $\mathrm{Z}$ стремится познавать новое и ориентировано на саморазвитие. Однако цифровые технологии сформировали у поколения $\mathrm{Z}$ клиповое мышление, что не совсем соответствует такому свойству, как усердно работать над чем-либо ради саморазвития и достижения сложной цели. В связи с этим однозначно утверждать, что стремление к обучению, самореализации и решение задач «на вырост» являются результатом влияния цифровой экономики, нельзя. Между тем, разнообразие как трудовая ценность, на наш взгляд, является результатом влияния цифровой экономики и четвертой промышленной революции, т. к. такие организационные и личностные свойства, как гибкость, адаптивность, изменчивость и др., актуализировались именно под влиянием технологий, в т. ч. цифровых.

По результатам проведенного анализа можно сделать вывод о том, что цифровая экономика оказывает непосредственное влияние на трудовые ценности молодого поколения ввиду ее воздействия на самые разные стороны жизни. Однако влияние цифровизации не является однолинейным процессом. По всей видимости, на трудовые ценности нового поколения оказывают влияние и другие факторы. Надо сказать, что цифровая экономика оказывает влияние на трудовые ценности не только поколения Z, но и других поколений. Одним из доказательств данного утверждения является рост самозанятых граждан, фрилансеров самых разных возрастов по всему миру.

Таким образом, в результате анализа было выявлено, что цифровая экономика, безусловно, оказывает существенное влияние на формирование трудовых ценностей поколения Z. Однако на трудовые ценности влияют и другие факторы: политические, экономическая ситуация в регионе/мире, исторические события, происходящие в период рождения и взросления поколения, местный менталитет, особенности воспитания в данный период времени и т. д. 


\section{СПИСОК ЛИТЕРАТУРЫ}

1. Шваб К. Четвертая промышленная революция. - М.: Эксмо, 2016. - 138 с.

2. Kehal Harbhajan, Varinder Singh. Digital economy: impacts, influences and challenges. - Hershey; London; Melbourne; Singapore: IGI Global, 2005. - 424 p.

3. Программа «Цифровая экономика Российской Федерации»: распоряжение Правительства Российской Федерации от 28 июня 2017 года № 1632-p. URL: http://static.government.ru/media/files/ 9gFM4FHj4PsB79I5v7yLVuPgu4bvR7M0.pdf (дата обращения 12.12.2018).

4. Якимова 3.В., Масилова М.Г. Поколение $\mathrm{Z}$ как потенциальный сегмент // Азимут научных исследований: педагогика и психология. - 2017. - № 4. - С. 341-345.

5. Howe N., Strauss W. Generations: the history of America's future, 1584 to 2069. - New York: William Morrow \& Company, 1991. - 538 p.

6. Савельева И.М., Полетаев А.В. История и время. В поисках утраченного. - М.: Языки русской культуры, 1997. - 486 с.

7. Решетников О.В. Поколение Z и недалекое будущее рынка труда // Школьные теории. - 2014. № $1 .-$ C. $58-71$.

8. Sezin Baysal Berkup. Working with Generations X and Y in Generation Z period: management of different generations in business life // Mediterranean journal of social Sciences. - 2014. - V. 5. - № 19. - P. $218-229$.

9. Леонова М., Константинов А. Знакомьтесь, поколение Z // Эксперт online. - 2018. - URL: http://expert.ru/russian_reporter/2018/01/znakomtes-pokolenie-z/ (дата обращения 12.12.2018).

10. Кошарный В.П., Корж Н.В. Трудовые ценности и установки студенческой молодежи // Известия высших учебных заведений. Приволжский регион. - 2012. - № 1. - С. 126-135.

11. Салтанова C., Котомина O., Мерзлых Ю. Z-работники. Как компании удержать молодых сотрудников // Научно-образовательный портал IQ НИУ «ВШЭ». - $2018 . \quad$ - URL: https://iq.hse.ru/news/216387265.html (дата обращения 12.12.2018).

12. Fromm J. Gen $Z$ in the workforce: how to recruit and retain youth generations // Forbes. - 2018. - URL: https://www.forbes.com/sites/jefffromm/2018/07/03/gen-z-in-the-work-force-how-to-recruit-and-retainyouth-generations/\#4f5af7037569 (дата обращения 12.12.2018).

Поступила 15.12.2018 2. 
UDC 331.101.5:331.52-053.81

\title{
IMPACT OF THE DIGITAL ECONOMY ON LABOR VALUES OF GENERATION, ENTERING THE LABOR MARKET
}

\author{
Vyacheslav V. Aranzhin, \\ slava.mr.slava@mail.ru \\ Tomsk State University, \\ 36, Lenin avenue, Tomsk, 634050, Russia.
}

Vyacheslav V. Aranzhin, post-graduate student, Tomsk State University.

The relevance of this study lies in the fact that the digital economy has a significant impact on all spheres of public life without exception: transactions, business and business models of organizations, methods of communication between subjects, way of life, work, leisure. The young generation, which is just to enter the labor market, was born in the era of digital technology, which certainly influenced their values and behaviors, and therefore there is a need to assess the impact of the digital economy on the labor values of the generation entering the labor market. The study of labor values of generation $Z$ will help organizations (employers) to develop effective strategies of motivation, retention, creation of working conditions corresponding to the values of this generation. The aim of the research is to determine the mechanisms of the digital economy influence on the labor values of the generation entering the labor market. Methods: historical method, methods of logical, comparative, system analysis. Results. The author has considered the main features of the digital economy, carried out the analysis of the main characteristics of generation $Z$ on the basis of the review of foreign and domestic literature, defined labor values of generation $Z$ and assessed the influence of digital economy on labor values of the considered generation. It is suggested that the digital economy is not the only factor influencing the labor values of the modern generation.

Key words: Digital economy, fourth industrial revolution, digital technologies, generation Z, labor values, labor market, labor relations, motivation.

\section{REFERENCES}

1. Shvab K. Chetvertaya promyshlennaya revolyutsiya [The Fourth industrial revolution]. Moscow, Eksmo Publ., 2016. 138 p.

2. Kehal Harbhajan, Varinder Singh. Digital Economy: impacts, influences and challenges. Hershey, London, Melbourne, Singapore, IGI Global, 2005. 424 p.

3. Programma «Tsifrovaya ekonomika Rossiyskoy Federatsii» [Program «Digital economy of the Russian Federation»]. Rasporyazhenie Pravitelstva Rossiyskoy Federatsii ot 28 iyunya 2017 no. 1632-r [Order of the Government of the Russian Federation, June 28, 2017 no. 1632]. Available at: http://static.government.ru/media/files/9gFM4FHj4PsB79I5v7yLVuPgu4bvR7M0.pdf (accessed 12 December 2018).

4. Yakimova Z.V., Masilova M.G. Generation Z as a potential segment. Azimuth of scientific research: pedagogy and psychology, 2017, no. 4, pp. 341-345. In Rus.

5. Howe N., Strauss W. Generations: the history of America's future, 1584 to 2069. New York, William Morrow \& Company, 1991. $538 \mathrm{p}$.

6. Saveleva I.M., Poletaev A.V. Istoriya i vremya. V poiskakh utrachennogo [History and time. In search of the lost]. Moscow, Languages of Russian culture Publ., 1997. 486 p.

7. Reshetnikov O.V. Generation Z and the near future of the labor market. School theories, 2014, no. 1, pp. 58-71. In Rus.

8. Sezin Baysal Berkup. Working with Generations $\mathrm{X}$ and $\mathrm{Y}$ in Generation $\mathrm{Z}$ period: management of different generations in business life. Mediterranean journal of social Sciences, 2014, vol. 5, no. 19, pp. 218-229. 
9. Leonova M., Konstantinov A. Znakomtes, pokolenie Z [Meet generation Z]. Expert online, 2018. Available at: http://expert.ru/russian_reporter/2018/01/znakomtes-pokolenie-z/ (accessed 12 December 2018).

10. Kosharny V.P., Korzh N.V. Labor values and attitudes of the student youth. News of higher educational institutions. Privolzhsky region, 2012, no. 1, pp. 126-135. In Rus.

11. Saltanova S.V., Kotomina O., Merzlykh Yu. Z-rabotniki. Kak kompanii uderzhat molodykh sotrudnikov [Zworkers. How the company to retain young employees]. Nauchno-obrazovatelny portal IQ NIU «VSHE». Available at: https://iq.hse.ru/news/216387265.html (accessed 12 December 2018).

12. Fromm J. Gen $Z$ in the workforce: how to recruit and retain youth generations. Forbes, 2018. Available at: https://www.forbes.com/sites/jefffromm/2018/07/03/gen-z-in-the-work-force-how-to-recruit-and-retainyouth-generations/\#4f5af7037569 (accessed 12 December 2018).

Received: 15 December 2018. 